\title{
Impact of a Pilot Intervention to Improve Nutrition Knowledge and Cooking Confidence Among Low-Income Individuals
}

\author{
Stacey C. Driver ${ }^{1} \&$ Carol A. Friesen ${ }^{1}$ \\ ${ }^{1}$ Department of Family and Consumer Sciences, Ball State University, United States \\ Correspondence: Carol A. Friesen, Department of Family and Consumer Sciences, Ball State University, United \\ States. E-mail: cfriesen@bsu.edu
}

Received: October 10, 2015 Accepted: November 10, 2015 Online Published: December 28, 2015

doi:10.5539/jfr.v5n1p88

URL: http://dx.doi.org/10.5539/jfr.v5n1p88

\begin{abstract}
Poor dietary behaviors, limited food preparation skills, and low levels of self-efficacy toward preparing healthy meals have been indicated in low-income and food insecure populations. The purpose of this pilot intervention was to determine the effectiveness of a community cooking demonstration at increasing participants' general nutrition knowledge and confidence to prepare healthy meals with limited resources. Data was analyzed from a convenience sample of 23 low-income adults associated with Head Start $(n=8)$ or a local soup kitchen $(n=15)$ in the Midwestern United States. Participants attended a one-hour presentation comprised of a cooking demonstration, taste testing, and basic education on the MyPlate food guide and food safety. Subjects completed a pre- and post-assessment to measure changes in cooking confidence and general food and nutrition knowledge. Results indicated that, although there were no significant improvements in participants' confidence to prepare healthy meals $(39.3 \pm 11.3$ vs. $44.5 \pm 9.1 ; \mathrm{t}=1.76, \mathrm{p}=0.25)$, subjects experienced significant gains in knowledge related to the MyPlate food guide $(1.2 \pm 0.5$ vs. $1.8 \pm 0.8 ; \mathrm{t}=2.82, \mathrm{p}=0.01)$ and basic food safety $(0.7 \pm 0.9$ vs. $2.5 \pm 1.0 ; \mathrm{t}=6.05, \mathrm{p}<0.01)$. Further research is necessary to identify effective strategies for parlaying increased nutrition knowledge into improved self-efficacy and behavior change.
\end{abstract}

Keywords: self-efficacy, Head Start, food safety, low-income, cooking demonstration, nutrition education

\section{Introduction}

Adequate access to food of acceptable quantity and quality is necessary to provide the energy for growth, development, cognition, and physical function (Cook \& Frank, 2008). Unfortunately, millions of people in the United States do not have access to a plentiful food supply, and, thus, are considered to be food insecure (Coleman-Jensen, Nord, Andrews, \& Carlson, 2012). In 2013, 17.5 million households--14.3\% of households--in the United States were food insecure, meaning that those households had difficulty providing food for all of their members at some time during the year due to a dearth of resources (Coleman-Jensen, Gregory, \& Singh, 2014). Although data collected annually by the United States Department of Agriculture (USDA) indicates that overall food insecurity in the United States has decreased in the last two years, the prevalence of very low food security remains unchanged, with $5.7 \%$ of households reporting reduced food intake or disrupted meal patterns (Coleman-Jensen et al., 2014).

Experiencing low levels of food security can lead to devastating social, emotional, and physical consequences. These health problems include physical deficits, poor nutrition, and psychological distress associated with the instability of an inadequate food supply. Food insecure individuals have been found to have poor dietary intakes (Champagne et al., 2007; Eicher-Miller, Mason, Weaver, McCabe, \& Boushey, 2011; Tarasuk \& Beaton, 1999), face a greater risk of becoming overweight and obese (Adams, Grummer-Strawn, \& Chavez, 2003; Pan, Sherry, Njai, \& Blanck, 2012), and consequently, are more likely to experience poor general health (Cook et al., 2004; Kirkpatrick, McIntyre, \& Potesti, 2010; Stuff et al., 2004). In addition to physical detriments, those who are food insecure are also more likely to experience negative emotions such as anxiety, stress, sadness, and shame (Connell, Lofton, Yadrick, \& Rehner, 2005; Hamelin, Habicht, \& Beaudry, 1999; Walker, Holben, Kropf, Holcomb, \& Anderson, 2007). All of these deficits negatively impact an individual's overall wellness.

Although food insecurity exists across many demographic characteristics, one of the most predictive factors for being food insecure is income (Coleman-Jensen et al., 2012). Previous research has indicated that low-income populations are more likely to engage in unhealthy dietary behaviors, possess low levels of food preparation 
skills, and have limited self-efficacy, or confidence, in their own abilities to prepare healthy meals (McLaughlin, Tarasuk, \& Krieger, 2003; Mello et al., 2010; Mercille, Receveur, \& Potvin, 2012). These factors can render low-income individuals vulnerable to nutrition risks that may further compound the negative health outcomes associated with food insecurity.

As the problem of food insecurity in the United States persists, it is paramount that strategies to combat this problem be explored. Previous research has suggested nutrition education interventions as potential means for improving food-related knowledge and behaviors among low-income populations and, thereby, lessening the severity of food insecurity (Holben, 2010). A myriad of educational interventions focusing on teaching methods that include hands-on interactions, interactive demonstrations, and multimedia approaches have successfully improved nutrition knowledge, dietary behaviors, and confidence to prepare healthy meals (Campbell, Honess-Marreale, Farrell, Carbone, \& Brasure, 1999; Carney et al., 2011; Resnicow et al., 2000; Wrieden et al., 2007). Furthermore, prior intervention studies have demonstrated that providing nutrition education to low-income populations can alleviate the severity of food insecurity (Carney et al., 2011; Eicher-Miller, Mason, Abbott, McCabe, \& Boushey, 2009). Identifying successful methods for improving nutrition knowledge and behavior deficits, as well as self-confidence toward preparing healthy meals, may be a critical first step toward ameliorating food insecurity in the United States.

The aim of this pre- and post-research pilot study was to determine the effectiveness of a community-based nutrition education intervention at increasing confidence to prepare healthy meals using limited resources among low-income individuals.

\section{Method}

\subsection{Subject Recruitment}

The intention to conduct a nutrition intervention was announced to community stakeholders. Two locations providing services to low-income populations were selected as study sites. In order to encourage recruitment, flyer advertisements were displayed at the study sites and sent home with participants in the weeks leading up to the intervention. Additionally, as incentives for participation, all subjects received a free copy of the cookbook "Slow Cooking on a Budget," as well as a chance to win a slow cooker as a door prize. This study, including all data collection instruments and procedures, consent, methods, and educational curriculum, was approved by the Ball State University Institutional Review Board as an exempt study.

\subsection{Participants}

The population for this pilot study included a convenience sample of 25 low-income individuals associated with Head Start $(n=9)$ or a soup kitchen $(n=16)$ in the Midwestern United States. Both locations were identified as low-income community locations, and served as study sites and intervention venues. Inclusion criteria to participate in the study required that participants be at least 18 years of age. Subjects were self-selected to participate, with all participants 18 years of age and older expressing interest in the program being recruited to participate. The convenience sample yielded a diverse group of individuals varying by race, age, and gender.

\subsection{Program Development and Procedures}

Study participants attended a one-time, one-hour intervention consisting of a cooking demonstration, taste-testing of a prepared meal, and nutrition education presentation delivered in a community-based setting. The presentation included education on the topics of the MyPlate food guide and basic food safety. Food safety was chosen as the focus of this presentation because safe food is an important aspect of food security. Information on MyPlate was provided to demonstrate the components of a healthy diet and how to build a healthy meal. The cooking demonstration incorporated low-cost ingredients into a healthy, balanced family meal. The education presentation began with an introduction to MyPlate, followed by a demonstration of crockery cooking, which incorporated information about basic food safety. The MyPlate portion of the presentation focused on the five food groups, daily servings, and key consumer messages from the USDA website, www.choosemyplate.gov. The food safety portion of the presentation covered the topics of kitchen hygiene and time and temperature abuse.

Subjects completed a 12-item assessment to measure their cooking confidence and knowledge about nutrition and food safety both immediately preceding and following the intervention. All survey data was collected anonymously. Participant's pre- and post-assessment surveys were coded, allowing them to be paired for statistical analysis. 


\subsection{Assessment Tools}

The assessment tool utilized in the current study was developed by the researchers to evaluate the effectiveness of the intervention. Two Registered Dietitians and a public health professional specializing in community wellness reviewed the survey instrument for content and face validity. Questions used to assess the construct of cooking confidence were modeled after the previously validated instrument developed by Barton, Wrieden, and Anderson (2011) to evaluate community-based food skills interventions and subsequent gains in cooking confidence. Additional questions gauged changes in nutrition knowledge related to food safety and the MyPlate food guide. Participants were asked to complete a brief demographic form in addition to the 12-item questionnaire.

\subsection{Statistical Analysis}

All data from the paired pre- and post-assessment surveys were analyzed using SPSS v.19.0. Descriptive statistics, including means with standard deviations and frequency counts, were determined for all variables. Frequency counts (number and percent) were used to determine the overall prevalence of specific survey responses among study participants. The $\chi^{2}$ test was used to compare the demographic characteristics of the study subjects from the two study sites. Total cooking confidence, nutrition knowledge, and food safety knowledge scores (e.g., the sum of the correct number of responses for questions associated with each construct) were calculated. Paired t-tests were used to determine changes in participants' cooking confidence and knowledge scores following the intervention. The level of statistical significance for all analyses was set at $\mathrm{p} \leq 0.05$.

\section{Results}

\subsection{Subject Characteristics}

Program participants at Head Start and a local soup kitchen were invited to attend the nutrition education intervention. Of the 25 subjects self-selected to participate in the study, 23 individuals (Head Start= 8; Soup Kitchen= 15) completed the study in its entirety. One subject (Head Start) discontinued the intervention and another (Soup Kitchen) submitted incomplete survey instruments that were unusable for analysis. All subjects were 18 years of age or older. A description of subject demographics is presented in Table 1.

Table 1. Characteristics of the study subjects $(n=23)$

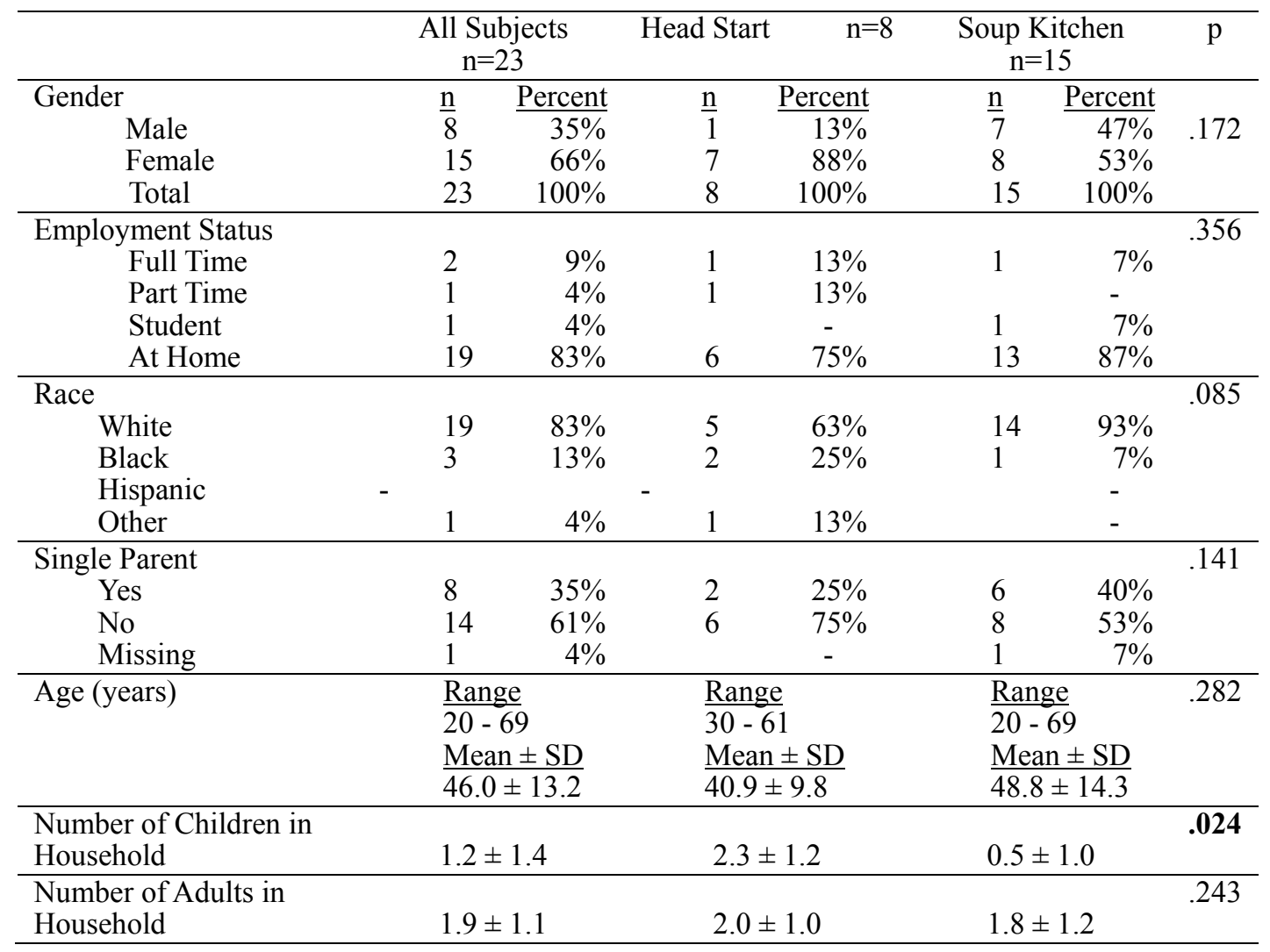


In order to ensure that subjects from the two study locations were similar populations, $\chi^{2}$ tests were used to compare demographics characteristics between the two groups. Results indicated that participants from Head Start and the soup kitchen were similar in terms of gender $(\mathrm{p}=0.172)$, employment status $(\mathrm{p}=0.356)$, race and ethnicity ( $\mathrm{p}=0.085)$, single parent status $(\mathrm{p}=0.41)$, age $(\mathrm{p}=0.282)$, and number of adults in the subject's household $(\mathrm{p}=0.243)$. However, Head Start participants had a greater number of children per household $(2.3 \pm 1.2)$ when compared with soup kitchen participants $(0.5 \pm 1.0)(\mathrm{p}=0.024)$ (Table 1).

\subsection{Impact of Intervention on Subjects' Cooking Confidence}

The pre- and post-test questionnaires included five questions addressing the topic of cooking confidence with optional responses rated on a Likert scale on a continuum from 0 (cannot do at all) to 10 (extremely certain can do). Participants responded by selecting the number on the continuum that they felt corresponded to their level of confidence in their own abilities related to the specific cooking behaviors in question. Responses from each question were compared pre-test to post-test using paired t-tests to monitor for change. Additionally, the five cooking confidence constructs were summed to create an overall cooking confidence score, which was also compared pre-test to post-test using a paired t-test to monitor for change. Results, as seen in Table 2, indicated that there were no significant improvements observed in individual constructs, or overall cooking confidence following the one-hour intervention.

Table 2. Paired analysis indicating change in cooking confidence following intervention

\begin{tabular}{lcccccc}
\hline & $\mathrm{n}^{*}$ & $\begin{array}{c}\text { Pre-Test } \\
\text { Mean } \pm \mathrm{SD}\end{array}$ & $\begin{array}{c}\text { Post-Test } \\
\text { Mean } \pm \mathrm{SD}\end{array}$ & $\begin{array}{c}\text { Mean } \\
\text { Difference }\end{array}$ & $\mathrm{t}$ & $\mathrm{p}$ \\
\hline Cooking from basic ingredients & 19 & $7.4 \pm 3.1$ & $8.7 \pm 2.2$ & 1.2 & 1.84 & .081 \\
Following a simple recipe & 20 & $9.2 \pm 1.7$ & $9.3 \pm 1.6$ & 0.1 & 0.33 & .745 \\
Tasting new foods & 21 & $7.1 \pm 3.1$ & $7.7 \pm 2.9$ & 0.6 & 0.88 & .389 \\
Preparing new foods & 20 & $8.0 \pm 2.6$ & $9.0 \pm 2.0$ & 0.9 & 1.34 & .196 \\
Preparing healthy, balanced meals & 21 & $8.1 \pm 2.2$ & $9.3 \pm 1.6$ & 1.1 & 2.06 & .052 \\
Summed Score: Self-Efficacy Questions 1-5 & $18^{\dagger}$ & $39.3 \pm 11.3$ & $44.5 \pm 9.1$ & 5.1 & 1.76 & .247 \\
\hline
\end{tabular}

$\mathrm{t}$ and $\mathrm{p}$ values for pre- and post-test comparison are based on paired T-test.

*Not all subjects responded to the self-efficacy questions on both the pre- and post-test assessments. Subjects with missing data were omitted from analysis.

${ }^{\dagger}$ Only 18 subjects responded to all five self-efficacy questions on both the pre- and post-test assessments, and thus were included in the summed score analysis

\subsection{Impact of Nutrition Education on Knowledge of the MyPlate Food Guide}

The survey instruments included three multiple-choice questions addressing the food groups and key consumer messages from the MyPlate initiative. Participants responded by choosing the answer choice they felt was correct. Responses to each question were coded as either "correct" or "incorrect" and compared pre-test to post-test using paired t-tests to monitor for change. Additionally, correct responses to the three MyPlate questions were summed to create an overall MyPlate knowledge score, which was also compared pre- to post-test using a paired t-test to monitor for change.

Results, as seen in Table 3, demonstrate that the number of correct responses increased from baseline for each of the three questions. At baseline, $30 \%$ of subjects $(n=7)$ were able to correctly identify that, according to the MyPlate initiative, half of a plate should be made up of fruits and vegetables. The amount of correct responses increased significantly to $65 \%(\mathrm{n}=15)$ following the intervention $(\mathrm{t}=3.21 ; \mathrm{p}=0.04)$. There was also a statistically significant improvement observed in the summed MyPlate knowledge score following the intervention. At baseline, the 23 subjects answered $1.2 \pm 0.5$ of the three questions correctly; following the intervention, participants answered $1.8 \pm 0.8$ of the three questions correctly. A paired t-test analysis indicated a significant positive change in overall knowledge of the MyPlate food guide $(\mathrm{t}=2.82, \mathrm{p}=0.010)$. 
Table 3. Paired analysis indicating change in knowledge of the MyPlate food guide following intervention

\begin{tabular}{|c|c|c|c|c|c|c|c|c|}
\hline \multirow[b]{2}{*}{ Q1: } & \multirow[b]{2}{*}{$\begin{array}{l}\text { Dry beans, eggs, } \\
\text { and nuts are part of } \\
\text { which group? }\end{array}$} & \multirow{2}{*}{$\begin{array}{l}\mathrm{n} \\
23\end{array}$} & \multicolumn{2}{|c|}{ Pre-Test } & \multicolumn{2}{|c|}{ Post-Test } & \multirow{2}{*}{$\frac{\mathrm{t}}{0.43}$} & \multirow{2}{*}{$\begin{array}{c}\mathrm{p} \\
.665\end{array}$} \\
\hline & & & $\frac{\text { N Correct }}{18}$ & $\frac{\text { Percent }}{78 \%}$ & $\frac{\text { N Correct }}{19}$ & $\frac{\text { Percent }}{83 \%}$ & & \\
\hline Q2: & $\begin{array}{l}\text { How much of your } \\
\text { plate should be fruits } \\
\text { and vegetables? }\end{array}$ & 23 & 7 & $30 \%$ & 15 & $65 \%$ & 3.21 & .004 \\
\hline Q3: & $\begin{array}{l}\text { Which of the } \\
\text { following is a whole } \\
\text { grain? }\end{array}$ & 23 & 5 & $22 \%$ & 9 & $39 \%$ & 1.73 & .096 \\
\hline
\end{tabular}

\subsection{Impact of Nutrition Education on Food Safety Knowledge}

The study questionnaire included four multiple-choice and true/false questions addressing general kitchen hygiene and time and temperature abuse. Participants responded by choosing the answer choice they felt was correct. Responses from each question were coded as either "correct" or "incorrect" and compared pre- to post-test using paired t-tests to monitor for change. Correct responses to the four food safety knowledge questions were summed to create an overall food safety knowledge score, which was also compared pre- to post-test using a paired t-test.

As seen in Table 4, results of the paired t-test indicated significant improvements in basic food safety knowledge for three of the four food safety questions, including questions about proper hand washing and the "Temperature Danger Zone" (TDZ). When the individual correct responses were summed to create the overall food safety knowledge score, there was a significant improvement in the subjects' knowledge of basic food safety concepts from pre- to post-test. On the pre-test, participants were unable to answered even one $(0.7 \pm 0.9)$ of the four questions correctly. Following the intervention, subjects were able to correctly answer $2.5 \pm 1.0$ of the four questions $(\mathrm{p}<0.001)$.

Table 4. Paired analysis indicating change in basic food safety knowledge following intervention

\begin{tabular}{lllllllll}
\hline & $\mathrm{n}$ & \multicolumn{2}{c}{ Pre-Test } & & Post-Test & $\mathrm{t}$ & $\mathrm{p}$ \\
\hline Q1: & $\begin{array}{l}\text { How long should } \\
\text { you wash hands? }\end{array}$ & 23 & $\frac{\text { N Correct }}{3}$ & $\frac{\text { Percent }}{13 \%}$ & $\frac{\text { N Correct }}{19}$ & $\frac{\text { Percent }}{83 \%}$ & 7.09 & $<.001$ \\
\hline Q2: & $\begin{array}{l}\text { What is the } \\
\text { Temp Danger Zone? }\end{array}$ & 23 & 3 & $13 \%$ & 20 & $87 \%$ & 6.55 & $<.001$ \\
\hline Q3: & $\begin{array}{l}\text { Should cooked food } \\
\text { be cooled at room } \\
\text { temp for 2-3 hrs } \\
\text { before storing? }\end{array}$ & 23 & 5 & $22 \%$ & 7 & $30 \%$ & 0.62 & .541 \\
\hline Q4: & $\begin{array}{l}\text { How long can foods } \\
\text { be in the TDZ before } \\
\text { they should be } \\
\text { thrown out? }\end{array}$ & 23 & 5 & $22 \%$ & 13 & $57 \%$ & 3.53 & $\mathbf{. 0 0 2}$ \\
\hline t and p values for pre- and post-test comparison are based on paired T-test. & & & & & & \\
\hline
\end{tabular}

\section{Discussion}

The present study delivered a cooking demonstration and nutrition education in an effort to increase nutrition knowledge and confidence to prepare healthy meals. No significant gains in cooking confidence were observed; however, participants did report increased knowledge following the intervention.

Although prior research has identified low levels of self-efficacy toward healthy meal preparation in low-income populations (Mercille et al., 2012; Winkler \& Turrell, 2009), it should be noted that participants in the current 
study reported relatively high levels of confidence toward meal preparation both prior to and following the intervention. Few studies have examined the impact of community-based interventions on cooking confidence. Moreover, no studies have attempted to improve this construct through a one-time intervention. Interventions that have successfully impacted long-term confidence toward cooking behaviors have consisted of sequential sessions over a longer period of time (Wrieden et al., 2007; Caraher, Seeley, Wu, \& Lloyd, 2013) Additionally, some studies have shown that cooking demonstrations alone are not effective at increasing cooking confidence, and that additional delivery methods may improve the success of community nutrition interventions. Interventions that include hands-on interaction and multimedia presentations have shown promising results with a variety of audiences (Levy \& Auld, 2004; Clifford, Auld, \& Champ, 2009; Campbell et al., 1999).

Participation in the one-hour nutrition education intervention led to a significant improvement in nutrition knowledge related to the USDA's MyPlate food guide. Curriculum for the intervention was designed to include key concepts from the MyPlate food guide because of its simplistic format and emphasis on building healthy meals. Other studies have incorporated curriculum from government dietary guidance as a means to successfully increase general nutrition knowledge in a variety of populations (Garcia-Lascurain, Kicklighter, Jonnalagadda, Boudolf, \& Duchon, 2006; Powers, Struempler, Guarino, \& Parmer, 2005; Rosenbloom, Kicklighter, Petacca, \& Deshpande, 2004). Improving knowledge is an important first step toward behavior modification (Contento et al., 1995; Henry, Reimer, Smith, \& Reicks, 2006). Other longer-term nutrition interventions seeking to impact cooking confidence and food insecurity have also incorporated nutrition education as a means to facilitate behavior change (Clifford et al., 2009; Resnicow et al., 2000; Eicher-Miller et al., 2009). In the current study, no long-term follow-up was conducted, so it remains unknown whether or not the participants' improved nutrition knowledge may have led to better dietary behaviors or improvements in cooking confidence following the intervention.

Food security involves not just having access to an adequate supply of food, but access to an adequate supply of safe food. It has been previously identified that some low-income individuals engage in unsafe kitchen practices to maintain food sufficiency in times of need (Kempson, Keenan, Sadani, Ridlen, \& Rosato, 2002; Kwon, Wilson, Beddnar, \& Kennon, 2008). Results of the present study indicated that the intervention was successful at significantly improving food safety knowledge in the target population. Throughout the nutrition intervention, participants learned about basic safe food handling practices. A narrow curriculum was chosen in order to focus on the most hazardous kitchen practices and so as not to overwhelm participants. This method is in line with the strategy recommended by Medeiros, Hillers, Kendall, and Mason (2001), which suggests food safety education focus on five behavioral constructs most likely to result in foodborne illness: personal hygiene, adequate cooking, cross-contamination, safe food temperatures, and obtaining food from safe sources. Participants in the present study seemed genuinely interested in this practical information, and many subjects asked questions about proper storage of various food items following the presentation.

This study brings to light some of the practical difficulties encountered when conducting research within the public health realm. Offering incentives for participation has been shown to be a powerful and successful recruitment strategy (Barnett, Aguilar, Brittner, \& Bonuck, 2012). In order to encourage subject recruitment and participation in the present study, free cookbooks were given to every participant and slow cookers were awarded as door prizes at the end of each presentation. Although providing incentives encouraged subject enrollment, it is possible that the recruitment strategy led to a study population that may not have been highly motivated to participate, as some participants did not express interest until the incentive was offered. In order to ensure full participation in the entire intervention, the incentives were withheld until after the post-test was completed and collected by the researchers. Another difficulty experienced during this project was the unpredictability of the study population. Previous research has shown that low-income populations often lead chaotic lives (Evans, Gonnella, Marcynyszyn, Gentile, \& Salpekar, 2005). Despite high levels of interest during the recruitment phase at Head Start, few participants showed up for the presentation and one was unable to complete the study due to intervening personal circumstances.

In addition to difficulties with subject recruitment, this study presents with some limitations, chiefly the lack of a control group and a small sample size. Additionally, study outcomes were measured using a very brief survey questionnaire. Although the study instrument was intentionally limited in scope and size, so as not to intimidate participants, more comprehensive data collection tools may yield more conclusive results in future research. Despite the current study's limitations, it also presents several strengths. This study incorporated a variety of educational strategies aimed at the sensory processes to appeal to participants' individual learning styles and was specifically tailored to the needs of low-income families. 


\section{Conclusion}

The results of this pilot study contribute to development and understanding of community-based nutrition education interventions. Although no significant gains in cooking confidence were observed, participants did report increased knowledge following the intervention. It is important to recognize that knowledge is a building block toward behavior change, and that, given time, increased nutrition knowledge may lead to improvements in confidence to prepare healthy, balanced meals. Food skills interventions such as the one described in this study are needed in this population because low-income families frequently prepare meals at home using limited resources. Future interventions that include a longer contact period and incorporate more hands-on activities, such as a cooking class as opposed to a cooking demonstration, may be more successful. Further research is needed to identify effective intervention strategies to aid low-income individuals in providing adequate, nutritious, and safe meals for themselves and their families.

\section{Acknowledgments}

The authors would like to thank Head Start of Delaware County, Indiana and Blood-N-Fire of Muncie, Indiana. Without their participation and support, this project would not have been possible.

\section{References}

Adams, E. J., Grummer-Strawn, L., \& Chavez, G. (2003). Food insecurity is associated with increased risk of obesity in California women. The Journal of Nutrition, 133, 1070-1074.

Barnett, J., Aguilar, S., Brittner, M., \& Bonuck, K. (2012). Recruiting and retaining low-income, multi-ethnic women into randomized controlled trials: Successful strategies and staffing. Contemporary Clinical Trials, 33(5), 925-932. http://dx.doi.org/10.1016/j.cct.2012.06.005

Barton, K. L., Wrieden, W. L., \& Anderson, A. S. (2011). Validity and reliability of a short questionnaire for assessing the impact of cooking skills interventions. Journal of Human Nutrition and Dietetics, 24, 588-595. http://dx.doi.org/10.1111/j.1365-277X.2011.01180.x

Campbell, M. K., Honess-Morreale, L., Farrell D., Carbone, E., \& Brasure, M. (1999). A tailored multimedia nutrition education pilot program for low-income women receiving food assistance. Health Education Research, 14(2), 257-267. http://dx.doi.org/10.1093/her/14.2.257

Caraher, M., Seeley, A., Wu, M., \& Lloyd, M. (2013). When chefs adopt a school? An evaluation of a cooking intervention in English primary schools. Appetite, 62, 50-59. http://dx.doi.org/10.1016/j.appet.2012.11.007

Carney, P. A., Hamada, J. L., Rdesinski, R., Sprager, L., Nichols, K. R., Liu, B. Y., ... Shannon, J. (2011). Impact of a community gardening project on vegetable intake, food security and family relationships: A community-based participatory research study. Journal of Community Health, 37, 874-881. http://dx.doi.org/10.1007/s10900-011-9522-z

Champagne, C. M., Casey, P. H., Connell, C. L., Stuff, J. E., Gossett, J. M., Harsha, D. W., ... Bogle, M. L. (2007). Poverty and food intake in rural America: Diet quality is lower in food insecure adults in the Mississippi Delta. Journal of the American Dietetic Association, 107(11), 1886-1894. http://dx.doi.org/10.1016/j.jada.2007.08.003

Clifford, D., Anderson, J., Auld, G., \& Champ, J. (2009). Good Grubbin': Impact of a TV cooking show for college students living off campus. Journal of Nutrition Education and Behavior, 41(3), 194-200. http://dx.doi.org/10.1016/j.jneb.2008.01.006

Coleman-Jensen, A., Nord, M., Andrews, M., \& Carlson, S. (2012). Measuring food security in the United States: Household food security in the United States in 2011. USDA Economic Research Service, Economic Research Report Number 141, Washington, DC, September 2012. Retrieved from http://www.ers.usda.gov/media/884525/err141.pdf

Coleman-Jensen, A., Gregory, C., \& Singh, A. (2014). Household food security in the United States in 2013. USDA Economic Research Service, Economic Research Report173, Washington, DC, September 2014. http://dx.doi.org/10.2139/ssrn.2504067

Cook, J. T., Frank, D. A., Berkowitz, C., Black, M. M., Casey, P. H., Cutts, D. B., ... Nord, M. (2004). Food insecurity is associated with adverse health outcomes among human infants and toddlers. The Journal of Nutrition, 134(6), 1432-1438.

Cook, J. T., \& Frank, D. A. (2008). Food security, poverty, and human development in the United States. Annals of the New York Academy of Sciences, 1136, 193-209. http://dx.doi.org/10.1196/annals.1425.001 
Connell, C. L., Lofton, K. L., Yadrick, K., \& Rehner, T. A. (2005). Children's experiences of food insecurity can assist in understanding its effect on their well being. The Journal of Nutrition, 135(7), 1683-1690.

Contento, I., Balch, G. I., Bronner, Y. L., Lytle, L. A., Maloney, S. K., Olson, C. M., ... Swadener, S. S. (1995). The effectiveness of nutrition education and implications for nutrition education policy, programs, and research: A review of research. Journal of Nutrition Education, 27(6), 277-418.

Eicher-Miller, H. A., Mason, A. C., Abbott, A. R., McCabe, G. P., \& Boushey, C. J. (2009). The effect of food stamp nutrition education on the food insecurity of low-income women participants. Journal of Nutrition Education and Behavior, 41, 161-168. http://dx.doi.org/10.1016/j.jneb.2008.06.004

Eicher-Miller, H., Mason, A. C., Weaver, C. M., McCabe, G. P., \& Boushey, C. J. (2011). Food insecurity is associated with diet and bone mass disparities in early adolescent males and not females in the United States. The Journal of Nutrition, 1738-1745. http://dx.doi.org/10.3945/jn.111.142059

Evans, G. W., Gonnella, C., Marcynyszyn, L. A., Gentile, L., \& Salpekar, N. (2005). The role of chaos in poverty and children's socioemotional adjustment. Psychological Science, 16(7), 560-565. http://dx.doi.org/10.1111/j.0956-7976.2005.01575.x

Garcia-Lascurain, M. C., Kicklighter, J. R., Jonnalagadda, S. S., Boudolf, E. A., \& Duchon, D. (2006). Effect of a nutrition education program on nutrition-related knowledge of English-as-Second-Language elementary school students: A pilot study. Journal of Immigrant and Minority Health, 8(1), 57-65. http://dx.doi.org/10.1007/s10903-006-6342-9

Hamelin, A., Habicht, J., \& Beaudry, M. (1999). Food insecurity: Consequences for the household and broader social implications. The Journal of Nutrition, 129(2S), 525S-528S.

Henry, H., Reimer, K., Smith, C., \& Reicks, M. (2006). Associations of decisional balance, processes of change, and self-efficacy with stages of change for increased fruit and vegetable intake among low-income, African-American mothers. Journal of the American Dietetic Association, 106(6), 841-849. http://dx.doi.org/10.1016/j.jada.2006.03.012

Holben, D. H. (2010). Position of the American Dietetic Association: Food insecurity in the United States. Journal of the American Dietetic Association, 110(9), 1368-1377. http://dx.doi.org/10.1016/j.jada.2010.07.015

Kempson, K. M., Keenan, D. P., Sadani, P. S., Ridlen, S., \& Rosato, N. S. (2002). Food management practices used by people with limited resources to maintain food sufficiency as reported by nutrition educators. Journal of the American Dietetic Association, 102(12), 1795-1799. http://dx.doi.org/10.1016/S0002-8223(02)90385-8

Kirkpatrick, S. I., McIntyre, L., \& Potesti, M. L. (2010). Child hunger and long-term adverse consequences for

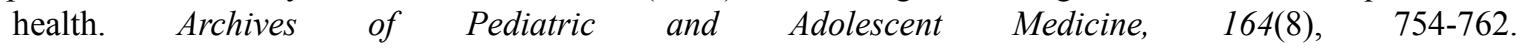
http://dx.doi.org/10.1001/archpediatrics.2010.117

Kwon, J., Wilson, A. N. S., Bednar, C., \& Kennon, L. (2008). Food safety knowledge and behaviors of Women, Infant, Children (WIC) program participants in the United States. Journal of Food Protection, 71(8), 1651-1658.

Levy, J., \& Auld, G. (2004). Cooking classes outperform cooking demonstrations for college sophomores. Journal of the American Dietetic Association, 107(9), 1502-1510. http://dx.doi.org/10.1016/s1499-4046(06)60234-0

Medeiros, L., Hillers, V., Kendall, P., \& Mason, A. (2001). Evaluation of food safety education for consumers. Journal of Nutrition Education, 33, S27-S34. http://dx.doi.org/10.1016/S1499-4046(06)60174-7

Mello, J. A., Gans, K. M., Risica, P. M., Kirtania, U., Strolla, L. O., \& Fournier, L. (2010). How is food insecurity associated with dietary behaviors? An analysis with low-income, ethnically diverse participants in a nutrition intervention study. Journal of the American Dietetic Association, 110(12), 1906-1911. http://dx.doi.org/10.1016/j.jada.2010.09.011

McLaughlin, C., Tarasuk, K., \& Krieger, N. (2003). An examination of at-home food preparation activity among low-income, food-insecure women. Journal of the American Dietetic Association, 103(11), 1506-1512. http://dx.doi.org/10.1016/j.jada.2003.08.022

Mercille, G., Receveur, O., \& Potvin, L. (2012). Household food insecurity and Canadian Aboriginal women's self-efficacy in food preparation. Canadian Journal of Dietetic Practice and Research, 73(3), 133-140. 
http://dx.doi.org/10.3148/73.3.2012.134

Pan, L, Sherry, B., Njai, R., \& Blanck, H. (2012). Food insecurity is associated with obesity in US adults in 12 states. Journal of the Academy of Nutrition and Dietetics, 112(9), 1403-1409. http://dx.doi.org/10.1016/j.jand.2012.06.011

Powers, A. R., Struempler, B. J., Guarino, A., \& Parmer, S. M. (2005). Effects of a nutrition education program on the dietary behavior and nutrition knowledge of second-grade and third-grade students. Journal of School Health, 75(4), 129-133. http://dx.doi.org/10.1111/j.1746-1561.2005.tb06657.x

Resnicow, K., Yaroch, A. L., Davis, A., Wang, D. T., Carter, S., Slaughter, L, .. Wang, D. T. (2000). Go Girls!: Results from a nutrition and physical activity program for low-income, overweight African American adolescent females. Health Education \& Behavior, 27(5), 616-631. http://dx.doi.org/10.1177/109019810002700507

Rosenbloom, C. A., Kicklighter, R. D., Patacca, R. D., \& Deshpande, K. (2004). Nutrition education in six congregate meal sites improves participants' nutrition knowledge. Journal of Nutrition for the Elderly, 23(3), 73-83. http://dx.doi.org/10.1300/J052v23n03_05

Stuff, J., Casey, P., Szeto, K., Gossett, J., Robbins, J., Simpson, P., ... Bogle, M. (2004). Household food insecurity is associated with adult health status. The Journal of Nutrition, 2330-2335.

Tarasuk, V. S., \& Beaton, G. H. (1999). Women's dietary intakes in the context of household food insecurity. The Journal of Nutrition, 129, 672-679.

Walker, J. L., Holben, D. H., Kropf, M. L., Holcomb, J. P., \& Anderson, H. (2007). Household food insecurity is inversely associated with social capital and health in females from Special Supplemental Nutrition Program for Women, Infants, and Children in Appalachian Ohio. Journal of the American Dietetic Association, 107(11), 1989-1993. http://dx.doi.org/10.1016/j.jada.2007.08.004

Winkler, E., \& Turrell, G. (2009). Confidence to cook vegetables and the buying habits of Australian households. Journal of the American Dietetic Association, 109(10), 1759-1768. http://dx.doi.org/10.1016/j.jada.2009.07.006

Wrieden, W. L., Anderson, A. S., Longbottom, P. J., Valentine, K., Stead, M., Caraher, M., ... Dowler, E. (2007). The impact of a community-based food skills intervention on cooking confidence, food preparation methods and dietary choices- An exploratory trial. Public Health Nutrition, 10(2), 203-211. http://dx.doi.org/10.1017/S1368980007246658

\section{Copyrights}

Copyright for this article is retained by the author(s), with first publication rights granted to the journal.

This is an open-access article distributed under the terms and conditions of the Creative Commons Attribution license (http://creativecommons.org/licenses/by/3.0/). 